\title{
Correction to: Evidence of heterogeneous and unstable anisotropic settings beneath the Northeast Indian lithosphere from characterization of null splitting measurements
}

\author{
Debasis D. Mohanty ${ }^{1,2}$ (D) Poulommi Mondal ${ }^{2}$
}

Published online: 4 February 2022

(c) The Author(s) under exclusive licence to Institute of Geophysics, Polish Academy of Sciences \& Polish Academy of Sciences 2022

Correction to: Acta Geophys. (2021) 69:2035-2050

https://doi.org/10.1007/s11600-021-00676-5

The publication of this article unfortunately contained a mistake. The name of the second author was not correct. Correct it should be P. Mondal.

The original article has been corrected.

The original article can be found online at https://doi.org/10.1007/ s11600-021-00676-5.

Debasis D. Mohanty

devlinkan06@yahoo.com; debasis@neist.res.in

1 Geosciences and Technology Division, CSIR - North East Institute of Science and Technology, Jorhat, Assam, India

2 Academy of Scientific and Innovative Research (AcSIR), Ghaziabad, India 